\title{
Application of Hybrid Modeling for Calculating Interturn Voltages in Transformer Windings
}

\author{
Gerben Hoogendorp, Student Member, IEEE, Marjan Popov, Senior Member, IEEE, and \\ Lou van der Sluis, Senior Member, IEEE
}

\begin{abstract}
This letter deals with the hybrid modeling of transformers and the determination of interturn voltage distribution in transformers with layer-type windings. The hybrid model uses a combination of a multiconductor transmission-line model and a single transmission-line model. The good agreement between computed and measured voltage waveforms shows that this model can be used for the computation of interturn voltages with full success. Analysis is performed by making use of a step function with 100-ns rise time.
\end{abstract}

Index Terms-Hybrid model, modified Fourier transform, very fast transients.

\section{INTRODUCTION}

$\mathbf{C}$ OMPUTATION of interturn voltages in transformers is of great importance for the design of transformer insulation. Very fast transients can be produced by lightning or transformer switching that can result in higher interturn voltages than the overvoltages produced by lightning impulse waves defined by the standards. In this work, an accurate computation of voltage transients is performed by making use of the hybrid model based on simplified Telegrapher's equations. It is verified that this way of modeling can also be used for layer-type transformers with full success.

\section{Methodology}

When each turn in a transformer is represented by a transmission line, the computation of the waveforms in the turns is accomplished by the modified Telegrapher's equations described by

$$
\begin{aligned}
\frac{\partial \mathbf{V}_{\mathrm{t}}}{\partial x} & =-\mathbf{L}\left(\frac{\partial \mathbf{I}_{\mathrm{t}}}{\partial t}\right) \\
\frac{\partial \mathbf{I}_{\mathrm{t}}}{\partial x} & =-\mathbf{C}\left(\frac{\partial \mathbf{V}_{t}}{\partial t}\right)+C_{0}[1] \frac{\partial E_{0}}{\partial t}
\end{aligned}
$$

where $\mathbf{V}_{\mathrm{t}}$ and $\mathbf{I}_{\mathrm{t}}$ are the voltage and current vectors, respectively, whereas $\mathbf{L}$ is the inductance matrix and $\mathbf{C}$ is the capacitance matrix. Both are square matrices and their order is equal to the number of turns. $C_{0}$ and $E_{0}$ denote the capacitance from

Manuscript received May 30, 2008; revised January 19, 2009. First published June 10, 2009; current version published June 24, 2009. Paper no. PESL-000622008.

The authors are with the Delft University of Technology, Faculty of Electrical Engineering, Mathematics and Computer Science, Delft 2628CD, the Netherlands (e-mail: M.Popov@tudelft.nl).

Color versions of one or more of the figures in this paper are available online at http://ieeexplore.ieee.org.

Digital Object Identifier 10.1109/TPWRD.2009.2021021 a turn to a static plate and excitation voltage, respectively. The voltage and current vectors of the modified Telegrapher's equations are

$$
\begin{aligned}
\mathbf{V}_{\mathbf{t}}(x) & =\mathbf{k}_{\mathbf{i}} E_{0}+\mathbf{A}_{\mathbf{t}} \exp (-\Gamma(\omega) x)+\mathbf{B}_{\mathbf{t}} \exp (\Gamma(\omega) x) \\
\mathbf{I}_{\mathbf{t}}(x) & =v_{s} \mathbf{C}\left(\mathbf{A}_{\mathbf{t}} \exp (-\Gamma(\omega) x)-\mathbf{B}_{\mathbf{t}} \exp (\Gamma(\omega) x)\right)
\end{aligned}
$$

where $\mathbf{A}_{\mathbf{t}}$ and $\mathbf{B}_{\mathbf{t}}$ are vectors, the parameters of which can be calculated by equating voltages and currents at the end of one line with the beginning of the next line, and $\mathbf{k}_{\mathbf{i}}$ is a vector of the capacitive distributed voltage. The propagation constant $\Gamma$ in (2) can be approximated by

$$
\Gamma=\frac{1}{v_{s} d} \sqrt{\frac{\omega}{2 \sigma \mu}}+\frac{\omega \tan \delta}{2 v_{s}}+\frac{j \omega}{v_{s}}
$$

where

$$
\begin{array}{ll}
v_{s} & \begin{array}{l}
\text { propagation speed of the surge (in meters per } \\
\text { second); }
\end{array} \\
d & \begin{array}{l}
\text { distance between the conductors (in meters); } \\
\mu
\end{array} \\
\sigma & \begin{array}{l}
\text { is magnetic permeability (in Henries per meter); } \\
\text { conductivity of the conductor (in Siemens per }
\end{array}
\end{array}
$$

Frequency-dependent losses in the winding are taken into account in the first term of the propagation constant. The second term accounts for dielectric losses represented by $\tan \delta$. The model also requires the characteristic impedance of the turns $z i$ which is determined by

$$
z i=\frac{1}{v_{s}\left(C_{0}+C_{1}+K\left(1-\cos \left(\frac{\omega a}{v_{s}}\right)\right)\right)}
$$

where $a$ is a turn length in meters while equivalent $K$ and $C_{1}$ are capacitances. More about the computation of $K, C_{1}$ and $\mathbf{k}_{\mathbf{i}}$ is reported [1].

The hybrid model is applied in the following way. First, transformer windings are divided into groups. For simplicity, we choose the same number of groups with the same number of turns within a group. Then, the voltages at the end of each group are calculated by applying the STLM. STLM means that a layer is considered as one transmission line. Knowing the voltages at the beginning and at the end of each group, the MTLM can be applied by taking into account that each turn is now a separate line. This significantly reduces the number of equations and the transformer is solved in two steps. The dimension of 


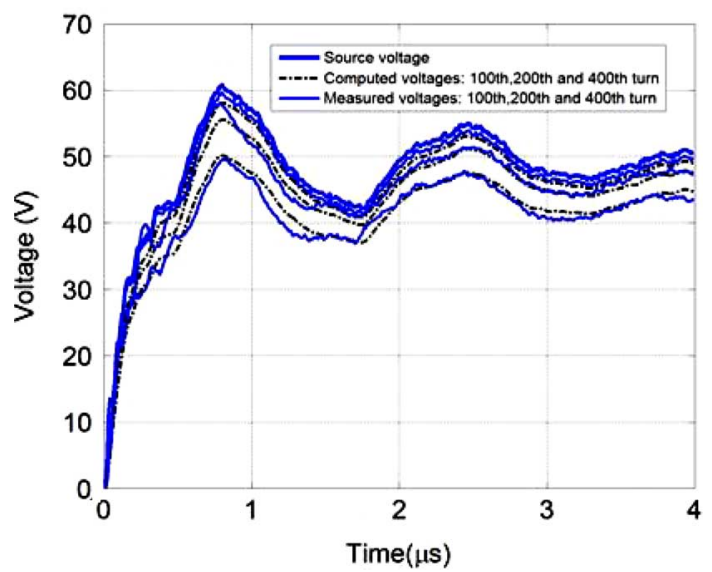

Fig. 1. Computed and measured voltages at the layers.

the $\mathbf{C}$ matrix in this case will be equal to the number of turns in a specific group. By determining the turn voltages, voltage differences between the turns can be computed. Since the transformer parameters are frequency dependent, the equations are transformed to the frequency domain and solved as algebraic equations. The observed frequency range is from 0 to $100 \mathrm{MHz}$. This frequency range is discretized into 10000 steps. For each frequency, by making use of (3) and (4), we calculate the propagation constant and the characteristic impedance. Then, $\mathbf{A}_{\mathbf{t}}$ and $\mathbf{B}_{\mathbf{t}}$ are determined and by applying (1), the voltages are calculated. Finally, the calculated voltages are transformed back to the time domain by using the modified inverse Fourier transform

$$
\delta V(t)=\frac{2 \exp (b t)}{\pi} \int_{-\Omega}^{\Omega} \frac{\sin \left(\frac{\pi \omega}{\Omega}\right)}{\left(\frac{\pi \omega}{\Omega}\right)} H(b+j \omega) \partial V(j \omega) d \omega .
$$

For an accurate time-domain response, the smoothing constant $b$, the interval of integration, and the step frequency length must be chosen properly [2].

\section{RESULTS}

The studied transformer is a $15-\mathrm{kVA}$ single-phase layer-type distribution transformer, with a transformer ratio of $6600 \mathrm{~V} / 69$ V. This transformer consists of 15 layers with 200 turns/layer. Transformer data applied for this study are shown in Table I. The input voltage and calculated voltages of specific turns are shown in Fig. 1.

Furthermore, time responses for the first $2 \mu \mathrm{s}$ with an approximated step function with a rise time of $100 \mathrm{~ns}$ are computed. Figs. 2 and 3 show the interturn voltage distribution in the first 20 turns and from the 120th to 140th turn in the first layer and the second layer, respectively. From computed results, it can be seen that the voltage amplitude gradually decreases, but there are no indications that the steepness of the voltage waveforms decreases accordingly. Voltage amplitudes are higher in the first coil than in the second, and the steepness of the waveforms, it is higher at the beginning of the layer and decreases toward the line-end coil
TABLE I

TRANSFORMER DATA

\begin{tabular}{|l|c|}
\hline \hline Inner radius of HV winding & $73.3 \mathrm{~mm}$ \\
\hline External radius of HV winding & $97.4 \mathrm{~mm}$ \\
\hline Inner radius of the LV winding & $51 \mathrm{~mm}$ \\
\hline External radius of LV winding & $67.8 \mathrm{~mm}$ \\
\hline Wire diameter & $1.16 \mathrm{~mm}$ \\
\hline Double wire insulation & $0.09 \mathrm{~mm}$ \\
\hline Distance between layers & $0.182 \mathrm{~mm}$ \\
\hline Coil's height & $250 \mathrm{~mm}$ \\
\hline Top / bottom distance from the core & $10 \mathrm{~mm}$ \\
\hline Dielectric Permittivity of oil & 2.3 \\
\hline Dielectric Permittivity of wire insulation & 4 \\
\hline \hline
\end{tabular}
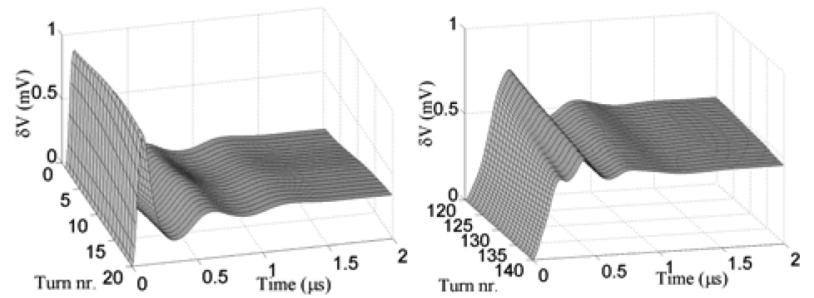

Fig. 2. Computed interturn voltage distribution of turns $1-20$ and turns $120-140$ in the first layer.
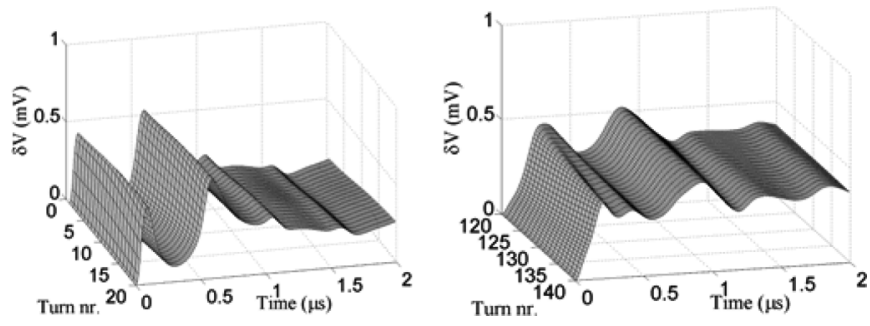

Fig. 3. Computed interturn voltage distribution of turn 0-20 and turns 120-140 in the second layer.

\section{CONCLUSION}

In this letter, the application of the hybrid transformer modeling based on the STLM and the MTLM is successfully applied on a distribution transformer with layer-type windings. By means of the STLM, voltages in line-end coils are computed. These voltages are applied to MTLM where each turn is represented by a transmission line. In this way, voltages in all turns are calculated. Time-domain solutions are provided by making use of the modified Inverse Fourier transform. The applied method is verified on a commercial transformer winding. Further analysis is performed by an approximated step function with 100 -ns rise time.

From the simulations, it can be concluded that interturn voltages with the highest amplitudes occur in the first layer, and the voltage steepness is higher at the beginning and decreases at the end of the layer. No internal resonance is found in the high-voltage winding of this transformer.

The developed method needs only data for the transformer geometry and insulation thickness. Based on these data, the applied method can be used to simulate the voltage distribution in 
layer-type transformers accurately. The method is applied only on the primary winding. Future possible work should consider the determination of the voltage distribution in the high-voltage winding and the low-voltage winding at the same time. Therefore, more attention should be paid to the surge transfer between the primary and the secondary winding.

\section{REFERENCES}

[1] Y. Shibuya, S. Fujita, and N. Hosokawa:, "Analysis of very fast transient overvoltages in transformer winding," Proc. Inst. Elect. Eng., Gen. Transm. Distrib., vol. 144, no. 5, pp. 461-468, Sep. 1997.

[2] J. P. Bickford, N. Mullineux, and J. R. Reed, Computation of Power System Transients. $\quad$ London, U.K.: IEE, Peregrinus, 1976. 